\title{
Computer-aided design of resonance-free vibration systems
}

\author{
Nikolai Muliukhin ${ }^{1}$, Dmitriy Lobanov ${ }^{1, *}$, Vladimir Grigoriev ${ }^{1}$, and Viktor Gartfelder ${ }^{1}$ \\ ${ }^{1}$ Federal State Educational Budget Institution of Higher Education «The Ulianov Chuvash State \\ University», 428015, Russia.
}

\begin{abstract}
The article provides insight into application of vibration systems in different industries. Disadvantages of conventional devices and advantages of resonance-free vibration systems are revealed. Issues of simulating resonance-free vibration systems, determination of main parameters and technical specifications of operating elements on the example of piling vibrators are discussed. The article dwells upon issues of computer-aided design of vibration systems, power, strength and kinematic calculations of main structure elements in NX, Euler, Ansys software systems. The provided algorithm enables reducing labor intensity of designing resonance-free vibration systems, reducing product cost and increasing the design engineer's performance. Prospects of further research on the subject matter are outlined.
\end{abstract}

At present vibration systems are used in different industries. They are used in devices, machines and aggregates: road construction machinery, mining industry, chemistry, construction, metallurgy, medicine, machine-building, etc [1-5].

The vibration systems that are used in industry create, during the process of operation, a large vibration field, which exceeds the permissible rates by characteristics. In adjacent fields, as a rule, resonance phenomena arise that often negatively affects the operability and durability of objects and workers' health and in some cases cause emergency situations.

In works [6-10] the authors dwelt upon issues of describing and simulating processes that take place in vibration systems, selecting their feasible characteristics, developing optimal designs; however, researchers pay little attention to the resonance phenomenon and reduction of its negative impact on the adjacent objects located within the vibration impact area. Use of resonance-free vibration systems can help significantly reduce negative impact of processes on machinery, environment and people within the working area.

Designing machinery based on resonance-free vibration systems without using computer-aided design recommendations and methods is a rather tedious, labor-intensive and expensive process. This leads to rising costs of devices, mechanisms and aggregates, which, in its turn, influences competitive performance of products[11-20].

Therefore, at present the relevant issues include not only simulation and automation of design, engineering and selection of feasible parameters of resonance-free vibration systems, but also creation of efficient methods of application of modern computing systems

${ }^{*}$ Corresponding author: shut tm@bk.ru 
for implementation of these processes. Their use will prevent errors in design, reduce labor intensity, cost of works and time for taking design solutions and increase engineer's performance and accuracy of calculations [20-23].

Let's take simulation of a vibrator used in construction for foundation strengthening to drive pile elements into sandy or clayey soils as an example of implementation of a systematic and methodological approach in designing of resonance-free vibration systems.

One needs to know technical specifications of the device under design for structural modeling. The force of driving (removal) of the driven element, amplitude of vibrations and other technical specifications of similar systems were selected as such. In the following, such input parameters of the model as the shaft rotation frequency and eccentric weights are selected based on the initial data.

Creation and operation of a vibration system model is based on main dynamics laws and system vibration theory. First, when mechanism shaft loads are known, plain bearings that meet operation requirements and conditions are selected. Then a 3D device model is built using NX 11 CAD graphic editor (Fig. 1).

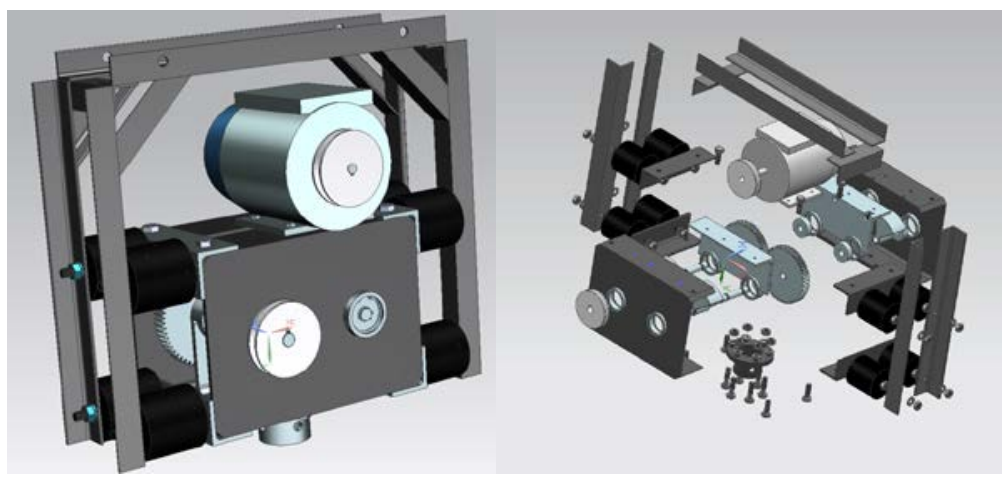

Fig. 1. Vibrator prototype 3D model.

A 3D model is used to determine the vibrator prototype mass-center data. After that a dynamic model is developed in Euler 10.11 Pro software based on the available data (Fig. 2).

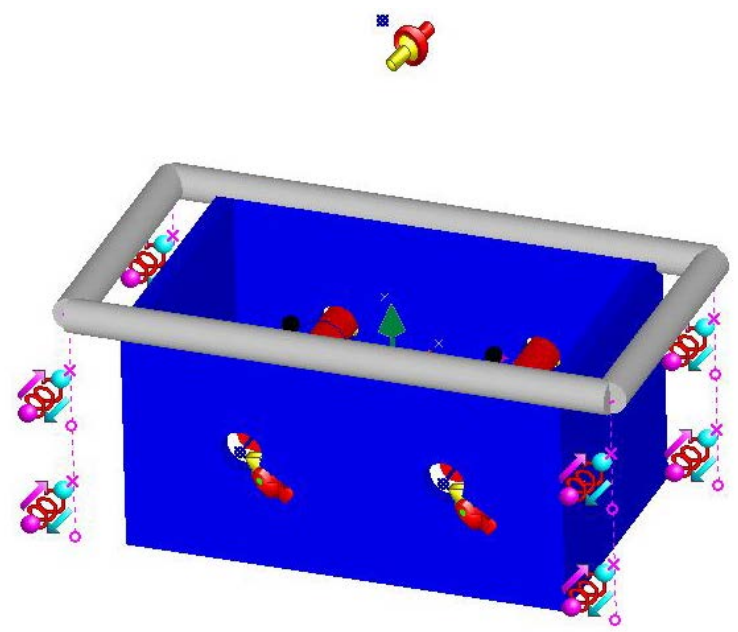

Fig. 2. Vibrator prototype dynamic model. 
When the required input parameters and mass-center characteristics have been introduced in the dynamic model, it is possible, by changing free parameters, to obtain set speeds, accelerations and other parameters of the device parts. An example in Fig. 3 shows the relationship between the driving shaft angular speed and operation time of different eccentric weights.

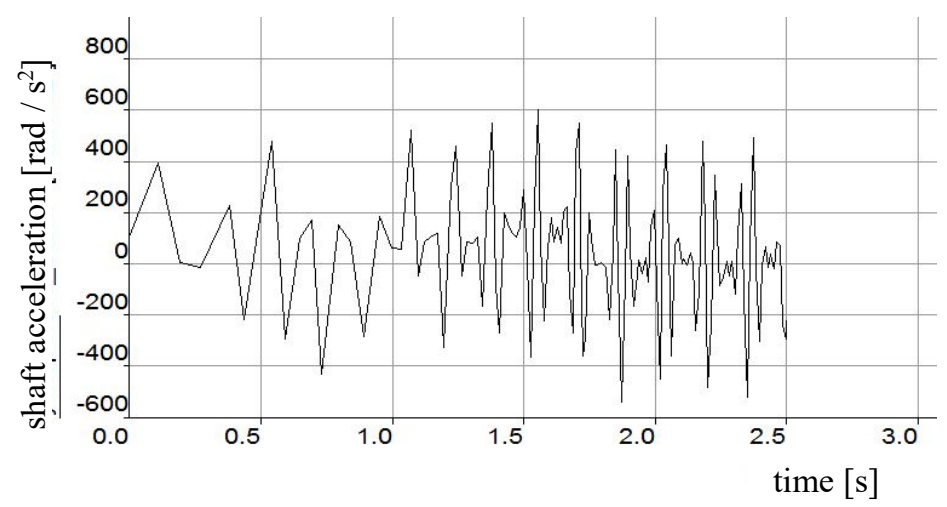

a)

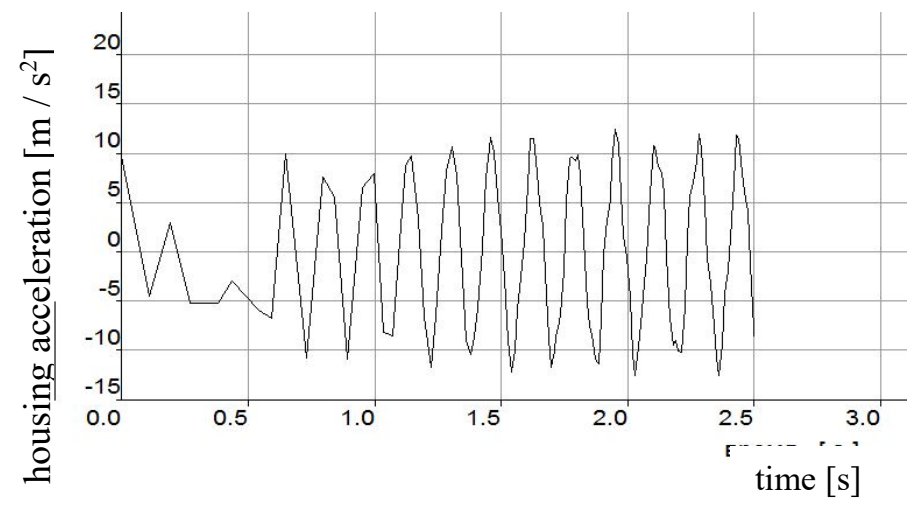

b)

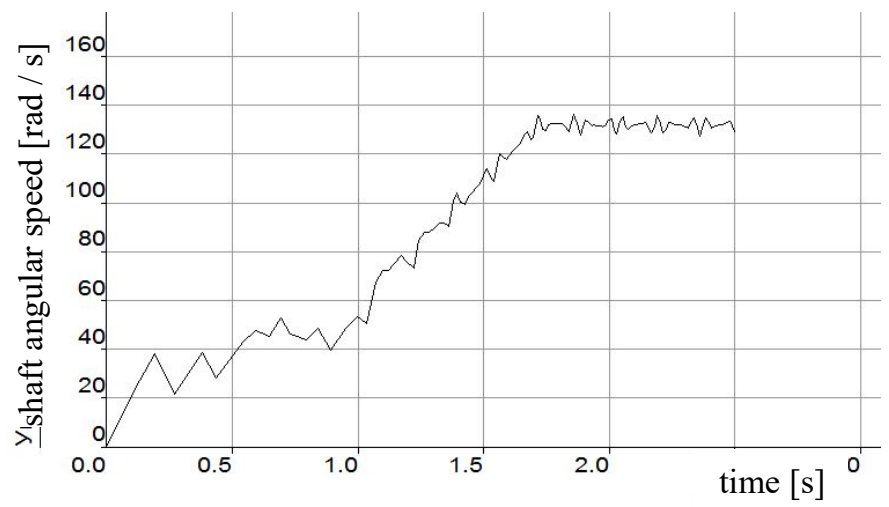

c)

Fig. 3. Diagrams of the relationship between vibrator prototype driving shaft acceleration at different torques: a) $1 N \cdot m$; b) $2 N \cdot m$; c) $3 N \cdot m$. 
After selection of optimal characteristics of the device under design, based on the results obtained from the dynamic model, for example, housing acceleration, spring force in Ansys R18 software system, we determine design peculiarities and operability of vibrator prototype parts. An example in Fig. 4 demonstrates results of strength calculations for different vibrator eccentric weight design solutions.

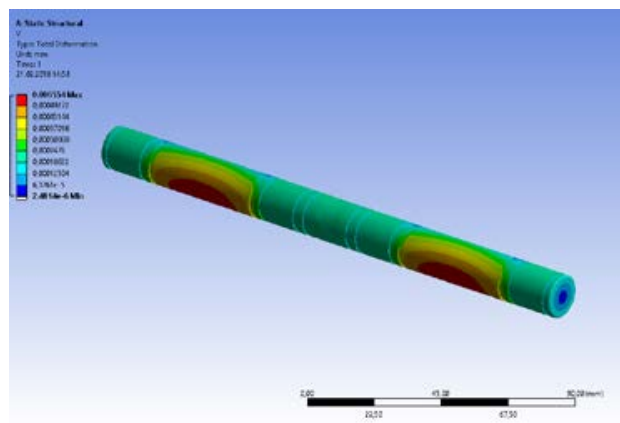

a)

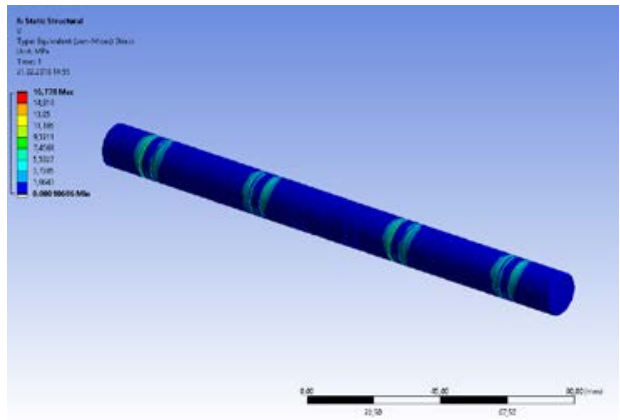

b)

Fig. 4. Driven shaft calculation models in Ansys R18 software system: a) deformations b) equivalent stresses

Use of the suggested computer-aided design and simulation methods enables reducing labor intensity of designing resonance-free vibration systems with variation of input parameters and design solutions, reducing the design calculation error, optimizing engineer's work, significantly simplifying the process of designing new systems and modernizing existing structures with account for calculation results obtained during simulation.

\section{References}

1. V.Yu. Skeeba, V.V. Ivancivsky, N.V. Martyushev, D.V. Lobanov, N.V. Vakhrushev, A.K. Zhigulev, Key Engineering Materials, T. 712, pp. 105-111, (2016)

2. P.V. Arkhipov, A.S. Yanyushkin, D.V. Lobanov, S.I. Petrushin, Applied Mechanics and Materials, T. 379, pp. 124-130, (2013)

3. A.S. Yanyushkin, D.A. Rychkov, D.V. Lobanov, Procedia Engineering 2. ser. "2nd International Conference on Industrial Engineering, ICIE 2016", pp. 942-947, (2016)

4. A. Yanyushkin, D. Lobanov, P. Arkhipov, V. Ivancivsky, Applied Mechanics and Materials,. T. 788, pp. 17-21, (2015)

5. A.S. Yanyushkin, D.V. Lobanov, D.A. Rychkov, Applied Mechanics and Materials, T. 770, pp. 739-743, (2015)

6. G. Panovko, A. Shokhin, S. Eremeykin, A. Gorbunov, Journal of Vibroengineering, T.17, №4, pp. 1903-1911, (2015)

7. Y.K. Ponomarev, International Journal of Engineering and Technology, T.6, №5, pp. 2225-2228, (2014)

8. D.V. Gorlatov, O.P. Tomchina, D.A. Tomchin, IFAC-PapersOnLine, T.48, №11, pp. 313-318, (2015)

9. S.Y. Levenson, L.I. Gendlina, Journal of Mining Science, T. 50, № 5, pp. 938-942, (2014) 
10. A.Ya. Tishkov, Yu.I. Eremenko, L.I. Gendlina, Journal of Mining Science, T.30, №2, pp. 175-177, (1994)

11. Y. Chen, H. B. Zhao, Z. P. Shea, Journal of Sound and Vibration, 160, 137-160. (1993)

12. B.A.J. Mustafa, R. Ali, Computers \& Structures, 32.2, pp. 355-363, (1989)

13. X. Zhao, K.M. Liew, T.Y. Ng, International Journal of Solids and Structures, 39.2, pp. 529-545, (2002)

14. S. R. Li, X. H. Fu, R. C. Batra, Mechanics Research Comunications, 37(3), pp. $577-$ 580, (2010)

15. A. Nayak, J.Bandyopadhyay, Journal of engineering mechanics, 131 (1), pp. 100-105, (2005)

16. S. Goswami, M. Mukhopadhyay, Journal of Composite Materials, 29 (18), pp. 23882422, (1995)

17. N. Wattanasakulpong, A. Chaikittiratana, Aerospace Science and Technology, 40, pp. 181-190, (2015)

18. A. Bhimaraddi, Int J Solids Struct, 27(7), pp.897-913,(1991)

19. N, Huang, Acta Mech, 108, pp. 23-34, (1995)

20. A. Khdeir, J. Reddy, Int J Solids Struct, 34(10), pp. 1217-1234, (1997)

21. D.V. Lobanov, P.V. Arkhipov, A.S. Yanyushkin, V.Yu. Skeeba, Key Engineering Materials, T. 736, pp. 81-85, (2017)

22. A.S. Yuanyushkin, D.A. Rychkov, D.V. Lobanov, Applied Mechanics and Materials, T. 682, pp. 183-187, (2014)

23. V. Pakhaliuk, A. Polyakov, M. Kalinin, S. Bratan, Tribology Online, T. 11, №1, pp. 527-539, (2016) 